\title{
Chapter 17 \\ Workplace-Based Training \\ in the European Union \\ and the Experience of Skillman
}

\author{
Giovanni Crisonà
}

\section{Abbreviations}

Cedefop European Centre for the Development of Vocational Training

CoVEs centers of vocational excellence

COVID-19 coronavirus disease

ETF European Training Foundation

IoT Internet of Things

PLCs Peer Learning Clubs

SAT Self-Assessment Tool

SAW Skills Anticipation Wave

SIF Skillman International Forum

SMEs small and medium-sized enterprises

TVET technical and vocational education and training

WBL work-based learning

\subsection{Introduction}

The Skillman Network is a nongovernment organization based in the European Union (EU) that is engaged in the technical and vocation education and training (TVET) domain to design and distribute work-based learning (WBL) solutions to address skills mismatch. Skillman is a worldwide community of practitioners, researchers, and institutions committed to responding to the need for learning solutions by

G. Crisonà (凶)

Skillman, Pistoia, Italy

e-mail: gc@ skillman.eu 
creating tools and operating conditions for its community, based on the principles of participatory learning and distributed collaboration.

According to the latest vision statement of the EU, companies expect workers to have the skills needed to master green and digital transitions, and to be able to get the right education and training to thrive in life (European Commission 2020b). The efforts needed to provide people with these rights require a TVET learning community that is able to reflect, identify, and share ideas, tools, and solutions; and above all, able to design frameworks that enable this progress to contribute to a wider opportunity for the development of a learning society.

To introduce these progressive adaptations, the chapter starts with the origins of Skillman, the background against which the network was formed, focusing on the EU policies and challenges associated with skills mismatch. The context in which the tools and solutions of the Skillman Network have evolved, their current features, and how they were designed and implemented in the era of the coronavirus disease (COVID-19) are discussed. The Skillman tools and the solutions presented in this chapter are Skills Anticipation Wave (SAW); Global Centres of Vocational Excellence (CoVEs) Framework, a transnational platform of CoVEs for emerging skills in advanced manufacturing; Peer Learning Clubs (PLCs); and Skillman's Self-Assessment Tool (SAT).

In relation to the challenges associated with the WBL approach to skills mismatch, the chapter presents a view that links all qualifications to education, labor market, and society. Skillman adopts solutions that have been designed and implemented over time for a large participative model of interaction among stakeholders. All of these converge into a discussion of the equitable approach to WBL, which connects curricula design with ethics and values; promotes inclusion and social cohesion; tackles adult unemployment and underemployment; and supports company and country policies and strategies for innovation, competitiveness, and growth (Cedefop 2015).

The chapter concludes with a presentation of Skillman solutions with a reflection on the meaning of "excellence" in TVET that Skillman members espouse; and the approach that the TVET community could take in this regard.

\subsection{How Skillman Forms Its Proposals for a Work-Based Learning Approach}

Skillman operates on a voluntary basis, and promotes a participative model and peer learning approach among its members. It pursues a sectoral skills model that includes sustainability and ethical values. Since 2014, values, principles, and solutions that the Skillman Network promotes have evolved to offer the most appropriate strategic tools to address industry needs, policies of the EU, and changes and influences coming from the international debate on education and training. During the COVID-19 pandemic, the European Commission put skills at the heart of its policy agenda, steering toward 
investment in people and their skills for a sustainable recovery. As a result, Skillman has recently incorporated the effects of the COVID-19 pandemic on TVET.

\subsubsection{Early Beginnings: Aligning Technical and Vocational Education and Training with Market Needs}

The European Commission launched in 2002 the Copenhagen Declaration, a European enhanced cooperation in vocational education and training (European Commission 2002). In 2010, the European Commission through the Bruges Communiqué called upon its members to support and ensure a better alignment of TVET with market needs to define new strategic objectives for TVET reform with the support of vocational excellence for smart and sustainable growth (European Commission 2010). Thereafter, the Sector Skills Alliances was created comprising three core groups of stakeholders, namely, industrial sectoral representatives, regulatory authorities, and TVET providers (European Commission 2014).

Starting from this decision, a group of stakeholders founded the Skillman Network in 2014, putting together industry leaders, research bodies, and TVET providers that included, among others, Fiat FCA, National Research Centre of the Italian Ministry of Education, University and Research, Jaguar Land Rover, and Scandinavian Airlines System.

With funding support from the EU, Skillman Network started operations in 2015, promoting a Sector Skills Alliance for Advanced Manufacturing (Crisonà 2017) to deliver concrete and innovative solutions to the skills needs in the field of advanced manufacturing for the transport, automotive, aerospace, and train sectors. Skillman began delivering around 60 units of learning and curricula in the fields of production and Industry 4.0, energy management, robotics, composite materials, etc. ${ }^{2}$

\subsubsection{Aligning Technical and Vocational Education and Training with Innovation Systems}

In 2017, the European Commission issued the Communication on Strengthening Innovation in Europe's Regions (European Commission 2017), pointing to the need to link TVET to innovation systems as part of the EU's smart specialization

\footnotetext{
${ }^{1}$ Founders in alphabetical order: Associazione Tecnica dell'Automobile Consulting \& Solutions srl/Italy, Birmingham Metropolitan College/UK, Centro Ricerche FIAT FCA/Italy, Centro Studi Cultura Sviluppo/Italy, CEPAS, Organismo di certificazione delle professionalità e delle competenze/Italy, Consiglio Nazionale delle Ricerche/Italy, Excellence, Achievement and Learning Ltd/UK, Industrens uddannelser/Denmark, Jaguar Land Rover Limited/UK, Scandinavian Airlines System Denmark-Norway-Sweden SAS/Denmark, Teknisk Erhvervsskole Center/Denmark.

${ }^{2}$ Source Skillman.eu. http://learn.skillman.eu/course/index.php?categoryid=11.
} 
strategies at a regional level. The Skillman Network presented its vision on how to integrate the skills anticipation lifecycle to the smart specialization platforms, defining a new approach called Skills Anticipation Wave (SAW). This concept, inspired by the salmon ascent route, focuses on the importance of continuously gathering information from all the actors involved in the innovation tunnels at a regional level; acquiring the latest information so that these can be promptly included in the TVET pathways; and effectively anticipating the skills needed by the labor market (Fig. 17.1).

\subsubsection{Integrating Technical and Vocational Education and Training with a Learning Society Approach}

In May 2018, the European Commission published its proposal for the new Erasmus+ Program 2021-2027 (European Commission 2018), indicating the need to develop transnational platforms of called Centres of Vocational Excellence (CoVEs). The proposal gives, for the first time, a substantial role to the EU CoVEs in contributing to a learning society approach, indicating that they have to become closely integrated in local and regional strategies for growth, innovation, and competitiveness; and to

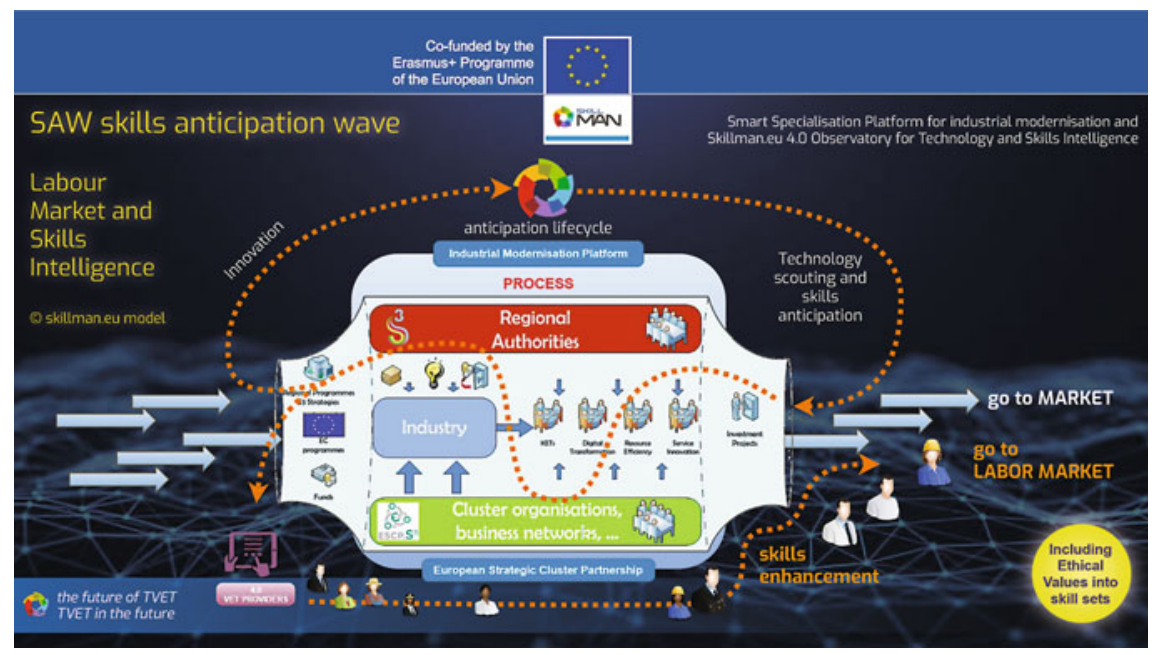

Fig. 17.1 Skills anticipation wave (The graphic shows the Skillman conceptual model of anticipation lifecycle applied within the organizational context of the Smart Specialization Platform of the European Commission). Note The orange arrows represent a process of continuous acquisition of information, done by Skillman's 4.0 Observatory for Technology and Skills Intelligence, and established to transfer detected skills needs into curricula design and learning pathways. CoVEs $=$ Centres of Vocational Excellence, SAW $=$ skills anticipation wave, TVET $=$ technical and vocational education and training. Source Skillman Network 
act as drivers of quality vocational skills in a context of sectoral challenges, while supporting overall structural changes and socioeconomic policies in the European Union.

Also in 2018, some 900 stakeholders joined the Fourth Skillman International Forum where they discussed solutions to integrate TVET in local and regional strategies for growth, innovation, and competitiveness. In addition, delegates discussed strategies in relation to the large interest and collaboration that the Skillman Network was forming on the ethical responsibilities of TVET, for inclusion in renewed strategies for lifelong learning and decentralized learning approaches.

During this time, the Skillman community had changed from a few dozen supporters to about 350 full partner volunteer members who, to better represent their vision and renewed composition, and in line with the latest EU trends, adopted their new definition of the Skillman Network: "Transnational platform of centres of vocational excellence for the emerging skills in advanced manufacturing" (ETF Team on Centres of Vocational Excellence 2020). The decision was taken to promote, disseminate, and encourage the community and members to act as drivers of excellence in TVET. In addition, to source and spread the Skillman vision, a Skillman magazine, CoVE-A Sectoral Skills Model that Includes Sustainability and Ethical Values, was launched, whose maiden issue was officially presented at the International Conference of Comparative and International Education Society held April 2019 in San Francisco.

To define more effectively its own support plan, the European Commission launched a study, Mapping of Centres of Vocational Excellence (CoVE), on the characteristics of centers of professional excellence, which was published in November 2019 (European Commission 2019).

Also in September 2019, a select group of Skillman members participated in the preparation of the Fifth Skillman International Forum, held October 2019, wherein the Skillman Network launched its Global CoVEs Framework (Crisonà et al. 2019), which is Skillman's flagship initiative for TVET quality improvement. The Skillman systematic approach to excellence in TVET, called Self-Assessment Tool (SAT), was also launched.

The SAT was designed by Skillman members as a subtle mechanism for the continuous evaluation and finetuning of 25 variables for excellence in TVET, to stimulate solid interaction and continuous learning among TVET stakeholders on the basis of concrete data.

The tool represents an approach to a networked vocational training system of the future that draws stakeholders' attention to real data in order to involve them to learn and improve from sharing standards and objectives.

By 2020, for the first time, the Global CoVEs Framework had operationalized the early version of $\mathrm{SAT}^{3}$ that of promoting a shared vison on the future of excellence in TVET (Table 17.1).

\footnotetext{
3“...implementing a self-assessment tool based on the maturity model-this would enable VET providers to identify areas for development and to access relevant support, e.g. good practice examples, peer learning activities" (European Commission 2019, p. 9).
} 
Table 17.1 General data from the first application of the survey

\begin{tabular}{|c|c|c|}
\hline $\begin{array}{l}\mathbf{1 0 3} \\
\text { Organizations surveyed }\end{array}$ & $\begin{array}{l}1742 \\
\text { Oldest year of constitution }\end{array}$ & $\begin{array}{l}\mathbf{2}, \mathbf{3}, \mathbf{4}, \mathbf{5}, \mathbf{6}, \mathbf{7}, \mathbf{8} \\
\text { EQF levels covered } \\
\text { by the group }\end{array}$ \\
\hline $\begin{array}{l}\mathbf{4 2 4 . 4 8 6} \\
\text { Learners }\end{array}$ & $\begin{array}{l}2019 \\
\text { Earliest year of constitution }\end{array}$ & $\begin{array}{l}1.202 \\
\text { Active projects in the } \\
\text { VET sector }\end{array}$ \\
\hline $\begin{array}{l}\mathbf{1 3 . 2 1 2} \\
\text { Teachers }\end{array}$ & $\begin{array}{l}17.794 \\
\text { Incubated companies }\end{array}$ & $\begin{array}{l}\mathbf{1 . 8 0 2} \\
\text { Number of publications } \\
\text { in the VET field in } 2018\end{array}$ \\
\hline $\begin{array}{l}\mathbf{8 4 . 1 8 0} \\
\text { Employees }\end{array}$ & $\begin{array}{l}\text { \%68,64 } \\
\text { Percentage of employees } \\
\text { who speak English }\end{array}$ & $\begin{array}{l}21.972 \\
\text { Computers }\end{array}$ \\
\hline \multirow[t]{2}{*}{$\begin{array}{l}\mathbf{1 . 3 7 1} \\
\text { New projects in the last } \\
3 \text { years }\end{array}$} & $\begin{array}{l}\mathbf{3 . 0 0 1 . 8 9 7} \\
\text { Total number of projects } \\
\text { from the constitution }\end{array}$ & $\begin{array}{l}€ 218.171 .499,29 \\
\text { Value in Euros of the owned } \\
\text { of didactic equipment }\end{array}$ \\
\hline & $\begin{array}{l}\mathbf{1 . 8 7 4} \\
\text { Agreements active with } \\
\text { other organisations }\end{array}$ & $\begin{array}{l}€ \mathbf{2 4 . 5 7 7 . 2 7 8 . 1 8 5 , 4 7} \\
\text { Annual turnover in Euros } \\
\text { Sum of all survey participants }\end{array}$ \\
\hline
\end{tabular}

Example of data collected with the first application of the Self-Assessment Tool survey, End-2019-February 2020

$\mathrm{EQF}=$ European Qualifications Framework, VET $=$ vocational education and training Source Skillman Network

To enable a shared learning experience among TVET stakeholders as a basis for a wider network of interconnected TVET providers, the SAT aims at continuous improvement of CoVEs by targeting the progress milestones indicated in the Maturity Model for CoVE Development (European Commission 2019), and by grouping performance under three clusters: (i) teaching and learning, (ii) cooperation and partnerships, and (iii) governance and financing or funding (Fig. 17.2).

In the last stage of its development, SAT allows for the following (see Fig. 17.3, steps 1-3):

(i) measuring and monitoring performance over time at the individual CoVEs level; territorial level (regional, national, and continental groupings); and framework level (all Global CoVEs members);

(ii) real-time publishing of visual presentations (radar maps) and definition of individualized concrete objectives (target levels) and standard levels; and

(iii) finetuning of the 25 variables for excellence (European Commission 2019), as integrated with the variables of the evaluation matrix in the Maturity Model for CoVE Development.

The SAT is consistent with the needs of the TVET sector for the following reasons: 


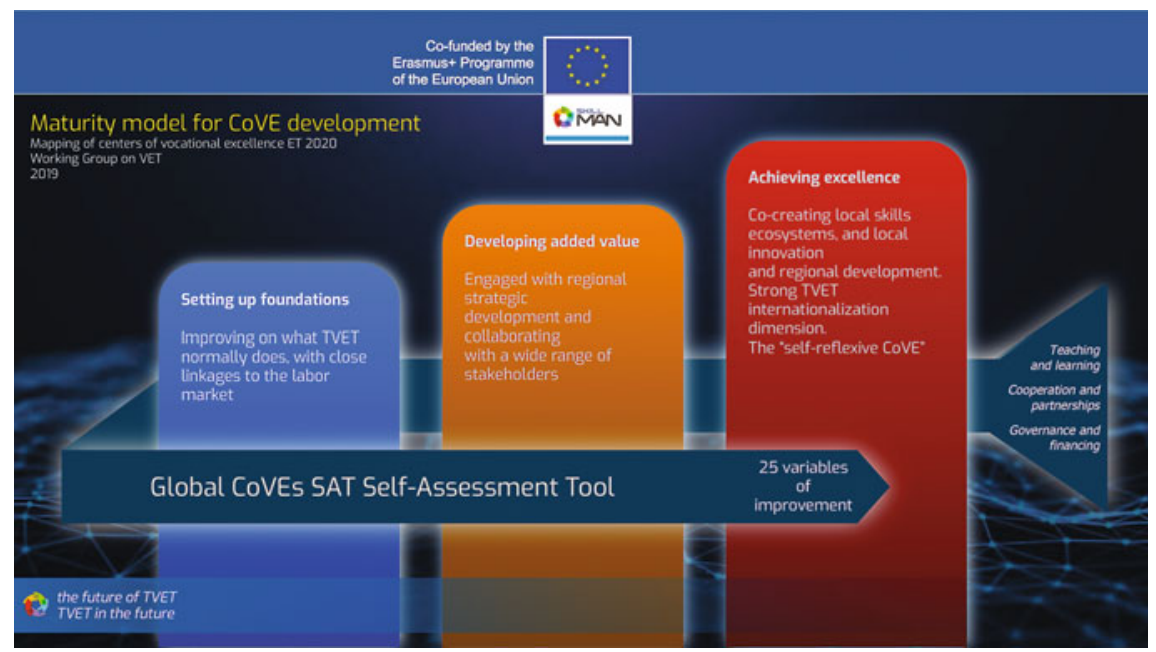

Fig. 17.2 Maturity model for development of centres of vocational excellence (The picture shows three pillars identified by the EU Working Group on VET in 2019 to bring CoVEs to achieve excellence in TVET, based on 25 variables implemented in SAT). CoVEs $=$ Centres of Vocational Excellence, $\mathrm{EU}=$ European Union, SAT $=$ Self-Assessment Tool, $\mathrm{TVET}=$ technical and vocational education and training. Source European Commission. 2019. Mapping of centres of vocational excellence (CoVEs). Luxembourg: Publications Office of the European Union. https://op.europa. eu/en/publication-detail/-/publication/566920f4-ee2d-11e9-a32c-01aa75ed71a1/language-en

(i) it allows scaling up of implementation to a large number of TVET providers and not only to the Global CoVEs members, ensuring a deep and wide impact;

(ii) it allows continuous self-assessments, audits, and certifications, enabling the creation of an accreditation system for CoVEs in advanced manufacturing;

(iii) it enables a transparent approach that facilitates efforts and recognition of excellence; and

(iv) it produces results that ensure the success of the matchmaking exercise for the best peer learning collaboration among the members of the platform. Each of the 25 variables are positioned in different stages of development of VET excellence.

\subsection{Principles and Settings to Examine in the Future of Work-Based Learning}

The launch of Skillman's Global CoVEs Framework involved selected members of the network and their related stakeholders with activities, which included an important debate to contribute to the formation of the Skillman Florence Declaration, TVET for Green, Sustainable and Inclusive Development in Response to the 


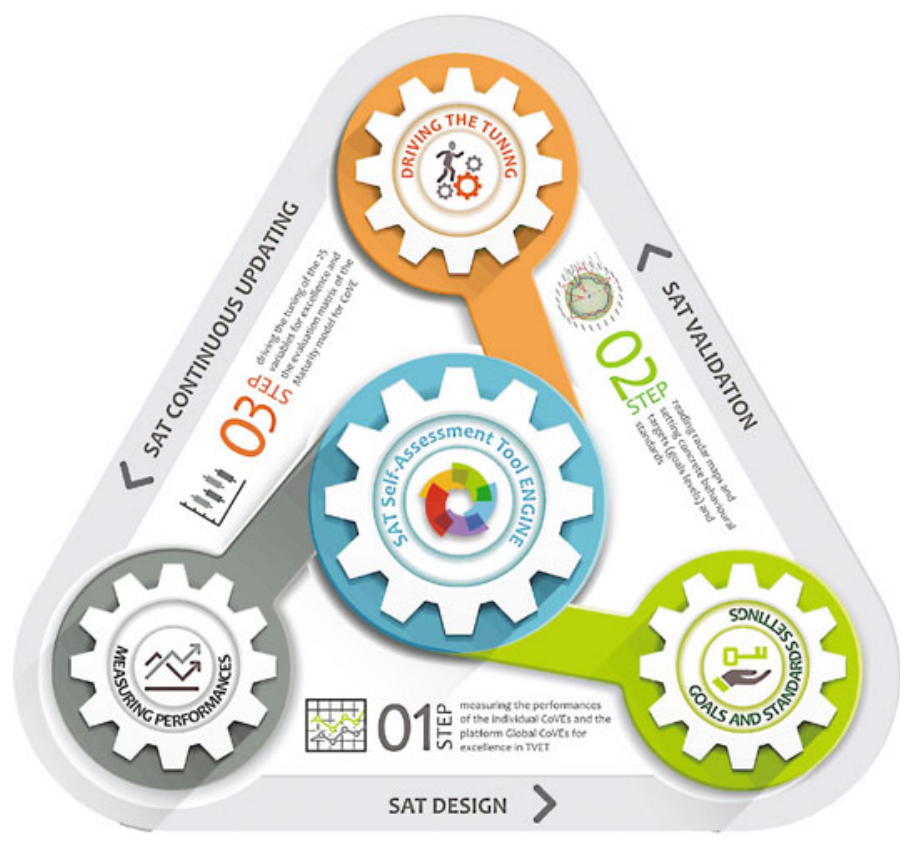

Fig. 17.3 Self-assessment tool (The picture presents the three steps in SAT application. Organizations collect their data into the system to start the design of their drives to excellence, set their own targets, validate the drives to be realized, and finally update their performance with a continuous application of actions for improvement. The model is conceived as a continuous exercise of analyses, planning, and execution). CoVEs $=$ Centres of Vocational Excellence, $\mathrm{SAT}=$ Self-Assessment Tool, TVET $=$ technical and vocational education and training. Source Skillman Network

Fourth Industrial Revolution, the Emerging Needs of Industry 4.0 and Ethical Considerations (Skillman.eu 2020).

The Skillman Florence Declaration was also adopted as a fundamental charter of reference for the Global CoVEs Framework. Global CoVEs is currently the learning framework of Skillman that helps its members produce innovation, new ideas, and proposals for change for a society that wishes to plan its future through curriculum design. The Global CoVEs Framework is consistent with the European Skills Agenda for sustainable competitiveness, social fairness, and resilience, which is also the latest initiative that the EU Commission introduced in July 2020 (European Commission 2020a) to extract Europe's competitiveness and innovation out of the COVID-19 pandemic effects.

Within the European Skills Agenda, the Pact for Skills puts skills at the heart of the EU's political agenda, and aims to mobilize member states, companies, and social partners for more and better opportunities for people to train and to unlock public and private investments in industrial and skills ecosystems (European Commission 2020a). 
For 2020-2021, under the aegis of the European Commission and also using the consultations format, the Skillman Network is implementing its "Skillnet Catalogue". 4 Skillnet Catalogue consists of a dense list of events and participatory meetings aimed at sharing Skillman's responses to the pandemic challenges relating to the fourth industrial revolution or Industry 4.0; emerging needs of Industry 4.0; green, sustainable, and inclusive development; and increasing importance of ethical issues.

The activities of the Skillnet Catalogue will stimulate a participatory peer learning approach, and usher the construction of a new vision on major changesmegatrends-that affect global and national economies and societies, to shape the future of education; provoke a natural flow of information; and facilitate the interaction of Skillman members and other stakeholders with different organizations and supranational bodies.

Participants are actively involved in the international debate on the future of TVET within a participatory learning and action cycle that encourages them to contribute to the formation of a common, critical, and constructive point of view for a fair and inclusive society. Such society addresses sustainable development issues by focusing on quality education and lifelong learning in the age of robotics; the Internet of Things (IoT); Big Data; TVET digitalization; and green, sustainable, and inclusive development.

Among its specific topics, this participatory process proposes the original Skillman.eu mission, which is the facilitation of the EU Skills Agenda designing new learning pathways in the advanced manufacturing sector. Also included is the particular debate that is still alive among the members, which is about the implementation of the 17 Sustainable Development Goals, with the awareness that more than ever, we need partnerships to innovate, transform, and fulfill the right to education (UNESCO 2019).

The same process was also related, in particular, to the ethical values that connect the competencies necessary for advanced manufacturing to the personal responsibility and to an increasing focus on the relevance of social networking (Box 17.1).

\section{Box 17.1 Work-Based Learning as a Key for Inclusion and Social \\ Cohesion}

The Skillman Network drives, into all its discussions, clear points to reflect an equitable approach to work-based learning (WBL). Skillman places a special focus on the relevance of WBL, not only because Skillman represents industries, but especially because of the potential of WBL to promote inclusion and social cohesion, to tackle adult unemployment and underemployment, and to support company and country policies and strategies for innovation, competitiveness, and growth.

\footnotetext{
${ }^{4}$ Skillman.eu. https://skillman.eu/skillnet-events.
} 
Source European Centre for the Development of Vocational Training (Cedefop). 2015. Work-based learning in continuing vocational education and training: policies and practices in Europe. Luxembourg: Publications Office of the European Union.

To address the policy makers and the general public with concrete proposals in the field of TVET, particularly its work-based forms, Skillman's participatory process is organized into four phases that run for specific periods. In the first phase or step, participants are actively engaged in groups called Peer Learning Clubs (PLCs) that begin to build their visions from the identification of challenges (Fig. 17.4).

The second step of their interaction consists in identifying existing and possible solutions. The third phase makes them involved in addressing their own counterparts to interact, discussing the proposals, and spreading the new ideas. Finally, the fourth phase merges all efforts in final documents that are circulated to the general public and among the stakeholders and policy makers.

The PLCs are composed of experts covering all roles (TVET providers, companies, governance representatives, and any other interested individuals) grouped to discuss, exchange ideas, and empower themself via online and on-site activities and using a bottom-up approach. They are organized into four specific objectives:

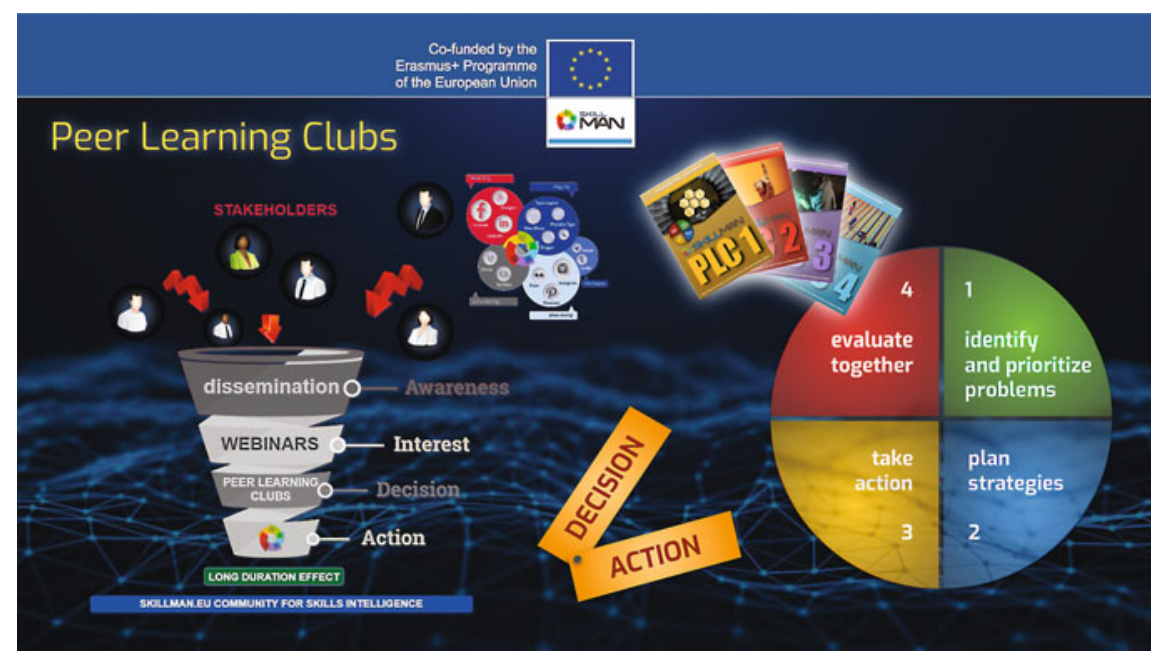

Fig. 17.4 Four phases in the peer learning club action cycle (Peer Learning Clubs start with engagement of stakeholders including TVET practitioners and industry experts who produce policy papers and other initiatives and campaigns to influence the policy arena. Through numerous dissemination activities such as webinars and other learning events offered by the Skillman Network, interested participants move to peer learning collaboration, producing their own concepts for innovation in TVET). CoVEs $=$ Centres of Vocational Excellence, PLC $=$ Peer Learning Club, $\mathrm{TVET}=$ technical and vocational education and training. Source Skillman Network 
(i) advanced manufacturing sector (sectoral dimension);

(ii) advocacy and policy influencing (empowering dimension, social equity dimension);

(iii) WBL and standards (WBL dimension, quality assurance dimension, curricular dimension); and

(iv) train-the-trainers (operational dimension).

These groups help to undertake large international events involving a considerable number of participants and promote a virtual international campus approach to finding ways, despite the current uncertainty of the pandemic, to build the basis for concrete mobility opportunities for trainers and students among connected CoVEs. In this respect, PLCs are preparatory to a lifelong learning activity that takes place according to a specific organization, and includes online workshops, working groups, sharing of best practices, open debates, etc.

\subsection{Answering the Need for More Skilled People}

The Skillman platform fosters the principles of the latest EU policy agenda on reforms and of the most relevant European key policy landmarks related to Industry 4.0. The 2020-2021 initiatives of the Skillnet Catalogue addressed to the Global CoVEs Framework are designed and realized in tandem by the Skillman Secretariat and the European Training Foundation, which focus on carrying out an innovative process of awareness-raising and broadening the audience of beneficiaries of the Global CoVEs Framework to redefine the future of learning.

These initiatives have led to a strengthened vision of the ethical concepts connected to competence-based training and allow the participants to discuss and agree on new ideas, solutions, and tools. In order to bring out ideas and proposals, the Skillman Stakeholders' debate expands its scope to several broad areas such as vocational excellence, artificial intelligence or AI, IoT, ethical values, TVET digitalization, green and inclusive development, and last but not the least, the issue of the challenges of the COVID-19 pandemic.

All the initiatives deployed by the Skillman members, even if they may look very different from each other, have a common root and share the same essence, that of the learning society, as they all aim to boost a learning community to promote excellence in TVET; plan future skills needs and learning pathways; and, finally, develop collaborative assessment and benchmarking approaches for better learning practice. Box 17.2 lists aspects of Skillman's agenda. 


\section{Box 17.2 The Skillman Agenda}

- Advance the contribution of technical and vocational education and training (TVET) and applied learning to green, sustainable, and inclusive development, in response to Industry 4.0 needs for a more qualified workforce and to particular challenges related to robotics, artificial intelligence, and the Internet of Things.

- Stress the increasing importance of ethical issues and social rights such as attention to gender discrimination, decent work, privacy rights, promotion of sustainable competitiveness, social fairness, and resilience.

- Promote the need to design curricula including ethical skills into learning pathways.

- Pursue a systematic approach to excellence in TVET.

Source Skillman Network.

The society of tomorrow requires an advanced manufacturing sector that needs a more qualified workforce with different profiles, endowed with skills and ethical values that currently are still lacking both in the labor market in general and in industrial companies in particular (i.e., in terms of numbers, knowledge, and know-how).

The tasks and capabilities of the suppliers who carry out the training courses require different approaches from the design phase to the manufacturing phasefrom the technician to be engaged in the factory, to the technologically skilled workers for particular tasks in specific industrial sectors.

As a result of the wide need for a qualified workforce and its importance at the operational level, the Skillman Network looks, within the Global CoVEs initiative, at improving the quality of TVET among its partner organizations, specifically structural and organizational changes for excellence.

In order to raise their ability to provide people with the missing skills through the provision of the right education and training, these partner organizations receive concrete and practical support to implement WBL solutions; to design trainings applying the "learning by doing" method; and to take advantage of all existing European tools and the most advanced solutions of WBL technologies such as the European Skills, Competences, Qualifications and Occupations classification database $^{5}$; European Qualifications Framework and/or European Credit System for Vocational Education and Training; Europass ${ }^{6}$; and Self-reflection on Effective Learning by Fostering the Use of Innovative Educational Technologies, ${ }^{7}$ among others.

\footnotetext{
${ }^{5}$ Source European Commission. Skills/competences. https://ec.europa.eu/esco/portal/skill.

${ }^{6}$ Source Europass. The European qualifications framework (EQF). https://europa.eu/europass/en/ european-qualifications-framework-eqf.

${ }^{7}$ Source European Commission. SELFIE. https://ec.europa.eu/education/schools-go-digital_en.
} 
As part of the Global CoVEs Framework, Skillman members seek to improve on their quality and respond to changes as required by industry and society. Global CoVEs is Skillman's flagship initiative for TVET quality improvement. The Global CoVEs Framework includes several organizations like the Austrian Federal Ministry of Digital and Economic Affairs, the Italian Ministry of Education, several regional authorities, and governments. In 2020, it was envisaged to have eight subgroups distributed across six countries in seven regions from the south, central, and northern regions of the European Union.

The initial composition of Global CoVEs was 36 full partner organizations, supported by an additional 96 associated partner organizations. The model of this collaboration is to pay attention to sustainability and ethical values in all EU countries and also outside the EU. The partnership is very rich and aligns a wide mix of complementary organizations representing TVET. Industry leaders like Fiat FCA, Toyota, Festo, Kohler-Lombardini, and even more SMEs that are linked through industry associations and clusters, all count as members (Box 17.3).

\section{Box 17.3 The Skillman Framework of "coves.eu"-Centres of Vocational Excellence}

The strengths of the coves.eu framework are as follows:

- a strong interaction capacity and collaboration among the companies and technical and vocation education and training (TVET) providers;

- a strong ethical commitment of all members;

- implementation of a tested method to deploy the skills foresight exercise;

- implementation of the Skillman Network's Self-Assessment Tool, currently considered a unique tool to assess and finetune excellence in TVET, and which implements a systematic approach;

- a strong connection with several available European Union tools; and

- the capacity to be embedded at the regional level within the European Union's Smart Specialization Strategies.

Source Skillman Network.

\subsection{Conclusions}

During the Skillman International Forum in 2019, Skillman members discussed the major "disruptors" and their implications for Skillman and work-based training. Five megatrends were identified that are affecting global and national economies and societies, which have implications for the European Union:

(i) global shifts such as rapid urbanization;

(ii) climate change, and resource scarcity; 
(iii) shift in global economic power;

(iv) demographic and social change; and

(v) technological breakthroughs that are changing the way we live and do business. $^{8}$

Their conclusion was that economic and workplace changes, which today include the COVID-19 pandemic first and foremost, are making human capital more and more important, driving Skillman members to conceive TVET as a homeostatic system that needs to raise its excellence at all levels and in all its components for a perfect integration with societal needs.

In line with this scenario and with recent policies of the EU, the challenges that the Skillman Network faces are focused on the promotion of excellence in TVET, although there are various distinctions and clarifications that Skillman members wish to make in fostering their participatory approach to excellence.

\subsubsection{Excellence with Ethics and Productivity Needs}

The network believes that particular attention should be paid to ethical and environmental principles aiming to understand and make the public reflect on the characteristics of the curricula we design today-the impact they may have on tomorrow's society. Also, how TVET organizations could help and what are the consequences of a TVET system that is limited only to responding to productivity needs, without considering the needs of a fair, peaceful, and green society fairly, are important concerns.

Skillman members consider the term "excellence" as a controversial term that is linked to the high quality of training and education, but which can also imply a wider, more complete, and inclusive conceptualization of the offer of competenciesaddressing innovation, pedagogy, social justice, lifelong learning, transversal skills, organizational and continuing professional learning, and community needs (ETF Team on Centres of Vocational Excellence 2020).

\subsubsection{Excellence of the Whole, not of the Elites}

Incorporating ethical values into skill sets and ensuring that no one is left behind is a concept that Skillman is putting into practice. Skillman is endeavoring to provide advanced manufacturing skills to everyone with a special focus on underdeveloped economies.

The gaps that the Skillman Network had sought to fill to promote excellence in TVET stems precisely from the lack of a broad approach in engaging TVET

\footnotetext{
${ }^{8} \mathrm{PwC}$. Megatrends: 5 global shifts changing the way we live and do business. www.pwc.co.uk/meg atrends.
} 
stakeholders so as to give them the opportunity to drive solutions together. There is a need to re-engineer TVET for change, to pursue a holistic approach. In this regard, Skillman has identified two important gaps:

(i) There is a gap in the understanding of excellence as a sustainable goal. A large aggregate of subjects aim at levelling up their performance not so much out of competition but to the exclusion of others who are not part of their own group.

(ii) There is a gap in the ability of TVET systems to connect the best performers to the weakest. In addition, there is a gap in the quantity and quality of the participatory opportunities that can improve the quality of the contributions that TVET stakeholders make to the future of education.

The question this author asks (compared to the solutions currently discussed in Europe to promote excellence in TVET), is whether it is still appropriate to strengthen some organizations that are already good performers with additional support and funds; or whether it would be more beneficial to understand excellence as a sustainable objective that must be targeted at large aggregates that also incorporate lower-level performers.

In this regard, the Skillman SAT is the new direction envisaged by the network. This tool in fact has the ethical aim of integrating the most powerful TVET organizations within an ecosystem where excellence does not belong only to an individual organization but is the result of the combined contribution of all members.

\subsubsection{A Digitalized Learning Society Today for the Society of Tomorrow}

This combination of efforts also leads to an analysis of Skillman's learning society approach to TVET changes. A perfect combination of TVET providers and companies to concretize the broad concept of a learning factory is a digitalized workplace full of sensors, which allows movement from the virtual to the real world, and which allows an effective integration of the learning environment into the production environment.

Skillman is promoting a bottom-up process to rethink what is required of TVET to meet the workforce and society's wider concerns within the advanced manufacturing sector. The new relevance that TVET is taking on in this context also points to the need to shift from the role of education to a more central role for TVET in helping to form the conscience of those who learn, because all qualifications have a role in education, in the labor market, and in society.

A good understanding of future skills needs with a bottom-up approach is therefore a natural and necessary consequence for TVET's roles in education, the labor market, and society, in order to coexist with rapid change and commitment to innovation.

Skillman Network members develop and revise curricula in various fields like robotics, IoT, composite materials, production management, digital and mechatronic, 
and other industrial occupations, in support of the transition to green and sustainable energy consumption. These curricula are designed today, but what the future needs is how TVET stakeholders can contribute to the design of tomorrow's society by being aware that tomorrow's society is in today's curricula.

In this process, learners have to become one of the most aware and responsible parties in curriculum design. The skills forecasting exercise presented with the Skillman Skills Anticipation Wave model is therefore not just a business process and cannot be limited only to education, but is a social project that needs broad consensus and interaction at all levels.

\section{References}

Crisonà, G. 2017. Partnerships for effective training to work transitions: A case study of the Skillman Alliance. Education Research for Policy and Practice 16: 95-107. https://doi.org/10.1007/s10 671-017-9212-4.

Crisonà, G., et al. 2019. Global CoVEs-The future of TVET/TVET in the future. Italy: Skillman. https://docs.google.com/document/d/1jIkP35ajS0HdXOVrWXtmVYACAH2NoiogoH3Bt9 noS9k/edit.

ETF Team on Centres of Vocational Excellence. 2020. Centres of vocational excellence: An engine for vocational education and training development: An international study. Luxembourg: European Training Foundation. https://www.etf.europa.eu/sites/default/files/202007/centres_of_vocational_excellence.pdf.

Europass. The European Qualifications Framework (EQF). https://europa.eu/europass/en/europeanqualifications-framework-eqf.

European Centre for the Development of Vocational Training (Cedefop). 2015. Work-based learning in continuing vocational education and training: Policies and practices in Europe. Luxembourg: Publications Office of the European Union.

European Commission. SELFIE. https://ec.europa.eu/education/schools-go-digital_en.

European Commission. Skills/competences. https://ec.europa.eu/esco/portal/skill.

European Commission. 2002. Declaration of the European ministers of vocational education and training, and the European Commission, convened in Copenhagen on 29 and 30 November 2002, on enhanced European cooperation in vocational education and training: "The Copenhagen Declaration". http://ec.europa.eu/education/policy/vocational-policy/doc/copenh agen-declaration_en.pdf; http://eose.org/wp-content/uploads/2014/05/copenhagen-declaration_ en.pdf.

European Commission. 2010. The Bruges Communiqué on enhanced European cooperation in vocational education and training for the period 2011-2020. http://ec.europa.eu/dgs/education culture/repository/education/policy/vocational-policy/doc/brugescom_en.pdf.

European Commission. 2014. Erasmus+ cooperation for innovation and the exchange of good practices (KA2) compendium 2014: Sector skills alliances. https://eacea.ec.europa.eu/sites/eaceasite/files/compendium-ssa-2014.doc.

European Commission. 2017. Communication from the Commission to the European Parliament, the Council, the European Economic and Social Committee and the Committee of the Regions. Strengthening innovation in Europe's regions: strategies for resilient, inclusive and sustainable growth. https://ec.europa.eu/regional_policy/sources/docoffic/2014/com_2017_376_2_en.pdf.

European Commission. 2018. Proposal for a regulation of the European Parliament and of the Council establishing "Erasmus": The Union programme for education, training, youth and sport and repealing Regulation (EU) No. 1288/2013. COM/2018/367 final-2018/0191 (COD). https:// eur-lex.europa.eu/legal-content/EN/TXT/?uri=COM:2018:367:FIN. 
European Commission. 2019. Mapping of Centres of Vocational Excellence (CoVEs). Luxembourg: Publications Office of the European Union. https://op.europa.eu/en/publication-detail/-/public ation/566920f4-ee2d-11e9-a32c-01aa75ed71a1/language-en.

European Commission. 2020a. European skills agenda for sustainable competitiveness, social fairness and resilience. https://ec.europa.eu/social/BlobServlet?docId=22832\&langId=en.

European Commission. 2020b. Questions and answers: European skills agenda for sustainable competitiveness, social fairness and resilience. https://ec.europa.eu/commission/presscorner/det ail/en/qanda_20_1197.

PwC. Megatrends: 5 global shifts changing the way we live and do business. www.pwc.co.uk/meg atrends.

Skillman.eu. http://learn.skillman.eu/course/index.php?categoryid=11.

Skillman.eu. https://skillman.eu/skillnet-events.

Skillman.eu. 2020. Florence declaration, final version. https://skillman.eu/skillman-florence-declar ation.

UNESCO. 2019. \#CommitToEducation. https://unesdoc.unesco.org/ark:/48223/pf0000370738?fbc lid=IwAR0Y0alhslzfGKefk15SBRH6NlXwgqGi9vU9Llkbk3kYh4r71rV2FOcJV6k.

The opinions expressed in this chapter are those of the author(s) and do not necessarily reflect the views of the Asian Development Bank, its Board of Directors, or the countries they represent.

Open Access This chapter is licensed under the terms of the Creative Commons Attribution-NonCommercial 3.0 IGO license (http://creativecommons.org/licenses/by-nc/3.0/igo/) which permits any noncommercial use, sharing, adaptation, distribution and reproduction in any medium or format, as long as you give appropriate credit to the Asian Development Bank, provide a link to the Creative Commons license and indicate if changes were made.

Any dispute related to the use of the works of the Asian Development Bank that cannot be settled amicably shall be submitted to arbitration pursuant to the UNCITRAL rules. The use of the Asian Development Bank's name for any purpose other than for attribution, and the use of the Asian Development Bank's logo, shall be subject to a separate written license agreement between the Asian Development Bank and the user and is not authorized as part of this CC-IGO license. Note that the link provided above includes additional terms and conditions of the license.

The images or other third party material in this chapter are included in the chapter's Creative Commons license, unless indicated otherwise in a credit line to the material. If material is not included in the chapter's Creative Commons license and your intended use is not permitted by statutory regulation or exceeds the permitted use, you will need to obtain permission directly from the copyright holder.

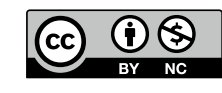

